\title{
A Comparison of Swallowing During Apnea and Periodic Breathing in Premature Infants
}

\author{
MARTHA J. MILLER AND JULIANN M. DIFIORE \\ Department of Pediatrics, Rainbow Babies and Childrens Hospital, Case Western Reserve University, \\ Cleveland, Ohio 44106
}

\begin{abstract}
Periodic breathing and apnea are two forms of ventilatory instability which are commonly observed in premature infants. This study was undertaken to characterize the pattern of swallowing during apnea and compare this pattern to that present during periodic breathing. We assessed the frequency and distribution of swallows during the respiratory pauses of apnea and periodic breathing in 22 premature infants birth weight $1.2 \pm 0.2 \mathrm{~kg}$, postconceptional age $34 \pm 2 \mathrm{wk}$. Twelve infants had apnea and 10 exhibited periodic breathing. During sleep the pharyngeal phase of swallowing was detected by a catheter in the pharynx and esophageal peristalsis by an
\end{abstract}

esophageal pressure catheter. Nasal airflow was monitored by a pneumotachometer. During apnea, the frequency of swallows was significantly greater than during the respiratory pauses of periodic breathing $(15.9 \pm 8.2$ versus $0.72 \pm 0.73$ swallows/min, respectively, $p<0.0001$ ) and also much higher than the rate of spontaneous swallows during sleep in either group $(0.66 \pm 0.66$ and $0.58 \pm 1.08$ swallows $/ \mathrm{min}$, respectively). We conclude that an increased rate of swallowing is characteristic of apnea in premature infants, and distinguishes apnea from the respiratory pauses of periodic breathing. (Pediatr Res 37: 796-799, 1995)
Premature infants may exhibit respiratory pauses of varying duration and pattern. Prolonged respiratory pauses of $10 \mathrm{~s}$ or more associated with bradycardia ( $<100$ beats/min) are generally referred to as apneic episodes, although the definition has varied (1-5). A clear-cut distinction cannot always be made between what is described as an apnea and other patterns of respiratory interruption which may occur in premature infants. Periodic breathing is a common abnormality of respiration in premature infants, which is characterized by regular bursts of ventilation, alternating with brief respiratory pauses (6). This has usually been considered to be a benign phenomenon because the respiratory pauses which occur are not associated with severe hypoxia or bradycardia. However, in some circumstances periodic breathing may indicate a pathologic state, for an increase in the frequency of periodic breathing has been identified as a risk factor in sudden infant death syndrome (7).

The exact relationship between apnea and periodic breathing is unclear: specifically, it is not known whether both types of respiratory pauses are produced by similar loci of inhibition within neuronal pathways to the muscles serving respiration. Previously, we have reported a striking similarity in the changes in pulmonary and upper airway resistance, respiratory drive, and duration of inspiration and expiration, which occur

Received August 22, 1994; accepted January 1, 1995

Correspondence: Martha J. Miller, M.D., Ph.D., Department of Pediatrics, Rainbow Babies and Childrens Hospital, 11100 Euclid Avenue, Cleveland, OH 44106. preceding and after the respiratory pauses of apnea and periodic breathing $(6,8)$. Although these similarities do exist, they do not prove that an identical disturbance in respiratory drive underlies both disorders.

Recently, Menon et al. (9) described an unusual characteristic of apnea in infancy. It was observed that repetitive swallows occurred during apnea at a higher frequency then during uninterrupted sleep. Theoretically, such swallows could prolong apnea through reflex inhibition of respiration. Therefore, the current study was undertaken to characterize and compare the pattern of spontaneous swallows during periods of apnea and periodic breathing in two groups of infants, one primarily exhibiting apnea at the time of study, and a second group with only periodic breathing. We speculated that, if apnea and periodic breathing share a similar etiology, spontaneous swallows should occur with the same distribution during both types of respiratory rhythm disturbance.

\section{METHODS}

The study population consisted of 22 premature infants: mean birth weight $1.2 \pm 0.2 \mathrm{~kg}$, mean postconceptional age at study $34.1 \pm 1.6 \mathrm{wk}$, mean postnatal age at study $4.9 \pm 2.0 \mathrm{wk}$. All infants had completely recovered from any respiratory distress; none required supplemental oxygen therapy at the time of study. Twelve infants had a history of apnea of prematurity and had continuing apnea at the time of study, but 
no periodic breathing. Ten out of 12 of these infants were receiving oral theophylline therapy (mean serum level $5.6 \pm$ $2.1 \mu \mathrm{g} / \mathrm{mL}$ ). Ten infants exhibited periodic breathing on routine cardiopulmonary monitoring; of these, five of this group were also receiving theophylline as therapy for previous episodes of idiopathic apnea but did not exhibit apnea at the time of study. Pulmonary and upper airway mechanics in the apneic infants have been previously reported (7). The investigation was approved by the institutional human research committee, and informed consent was obtained from the parents before study.

Experiments were performed in the neonatal physiology laboratory over a $60-90$-min period after each infant had been fed. During the study, nasal airflow was measured with a mask pneumotachometer and integrated to give tidal volume. Heart rate and $\mathrm{O}_{2}$ saturation were continuously recorded from a Nellcor N-100 pulse oximeter (Nellcor, Hayward, CA). Esophageal pressure was measured with a 5 French saline-filled catheter connected to a Statham PD 23 pressure transducer (Gould, Cleveland, Ohio). Oropharyngeal pressure was measured with a 5 French Millar pressure sensitive catheter, passed transnasally to $5.5-6 \mathrm{~cm}$ from the anterior nares (Millar Instruments, Houston, TX). The frequency response of all pressure catheters was evaluated with a square wave pressure change and was satisfactory to 12 $\mathrm{Hz}$. All experimental data were continuously recorded at a paper speed of $2 \mathrm{~mm} / \mathrm{s}$ on a Gould 8 -channel recorder and stored on magnetic tape.

For the purpose of this study, an apneic event was defined as a respiratory pause $\geq 10 \mathrm{~s}$ in duration, associated with at least a 20 -beat/min decrease in heart rate. Each apnea was classified as mixed, obstructive, or central according to the criteria previously used in studies from this laboratory (10). Mixed apnea was characterized by obstructed inspiratory efforts as well as a central pause greater than or equal to $2 \mathrm{~s}$ in duration. In central apnea, inspiratory efforts ceased entirely and obstructed breaths were not observed. During obstructive apnea, obstructed respiratory efforts continued throughout the apnea, but no nasal airflow occurred. Periodic breathing was defined as repeated ventilatory cycles of $\geq 4$ breaths/cycle, separated by discrete respiratory pauses of $\geq 2$-s duration (6). At least two consecutive minutes of repeated ventilatory cycles and respiratory pauses were analyzed in each infant with periodic breathing.

The pharyngeal phase of swallowing was characterized by a large positive wave on the pharyngeal pressure tracing with an amplitude $>5$ times the normal respiratory fluctuation in pharyngeal pressure (11). Esophageal peristalsis also could be identified by a positive pressure wave on the esophageal catheter tracing. The pattern of swallowing and accompanying esophageal peristalsis was characterized during a total of 38 apneic events in 12 infants and during a total of $59 \mathrm{~min}$ of periodic breathing in 10 infants.

For the comparison of the characteristics of two infant study groups, results were analyzed by unpaired $t$ test or Fisher exact test. For analysis of the swallowing pattern during apnea, analysis of variance, and the Newman-Keuls procedure for repeated measures were used. Data are expressed as mean $\pm \mathrm{SD}$.

\section{RESULTS}

The characteristics of the two groups of infants are shown in Table 1. No significant differences were found between the two groups of infants studied, in terms of birth weight, gestational age at study, days on supplemental oxygen therapy, or number of infants on theophylline at the time of study. Infants with periodic breathing exhibited $16.6 \pm 8.3 \mathrm{~min}$ of periodic breathing per study. The group of infants which exhibited apnea but no period breathing had a mean of three apneas per study, range one to nine, mean duration $18 \pm 9 \mathrm{~s}$. The distribution of types of apnea was $72 \%$ mixed, $23 \%$ central, and $5 \%$ obstructive.

The characteristics of spontaneous swallows were compared during periodic breathing and apnea in the two groups of infants. Spontaneous pharyngeal pressure waves resembling swallows occurred during the ventilatory pauses in 37 out of 38 apneas (97\%) (Fig. 1). The frequency of swallows was significantly higher at the beginning of an apnea ( $p<0.05$, Fig. 2 ); however, all apneas did not begin with a swallow. In fact, a swallow occurred within $3 \mathrm{~s}$ of the beginning of apnea (cessation of nasal airflow) in only $58 \%$ of apneas. Swallows were observed during all three types of apnea; mixed, obstructive, and central. The pharyngeal phase of swallows was followed by waves of esophageal peristalsis, which occurred at a mean frequency of three (range zero to three) swallows per esophageal peristalsis during apnea. In contrast, swallows were significantly less common $(0.72 \pm 0.73$ swallow/min $)$ during the respiratory pauses of periodic breathing $(p<0.0001$ compared with swallow frequency during apnea $15.9 \pm 8$ swallows/min) (Fig. 3). Swallow frequency during periodic breathing was essentially the same as the incidence of spontaneous swallowing during uninterrupted sleep in these infants $(0.66 \pm 0.66$ and $0.57 \pm 1.0 \mathrm{swallow} / \mathrm{min}$ in infants with apnea and periodic breathing, respectively).

\section{DISCUSSION}

This study has shown that swallows occurred with greatly increased frequency during apnea of prematurity, whether the type of apnea was mixed, obstructive, or central. These data are consistent with the results of Menon et al. (9) who previously described this phenomenon in premature infants with apnea. The current study extends these authors' previous observations to include a comparison of the phenomenon of swallowing during apnea and periodic breathing. We observed that, unlike

Table 1. Comparison of premature infants with apnea and periodic breathing

\begin{tabular}{|c|c|c|c|}
\hline & $\begin{array}{c}\text { Infants with } \\
\text { Apnea }\end{array}$ & $\begin{array}{c}\text { Infants with } \\
\text { Periodic } \\
\text { Breathing }\end{array}$ & $p^{*}$ \\
\hline$N$ & 10 & 12 & \\
\hline Birthweight (g) & $1156 \pm 346$ & $1342 \pm 242$ & 0.15 \\
\hline Gestational age at birth (wk) & $28.6 \pm 2.5$ & $29.9 \pm 1.8$ & 0.21 \\
\hline Gestational age at study (wk) & $34 \pm 1.5$ & $34 \pm 1.6$ & 0.63 \\
\hline Days on oxygen therapy & $15 \pm 20$ & $3.2 \pm 2.8$ & 0.07 \\
\hline Number of infants on theophylline & $10 / 12$ & $5 / 10$ & 0.098 \\
\hline
\end{tabular}

All data are expressed as mean \pm SD.

* Statistical comparison by unpaired $t$ test or Fishers exact test. 


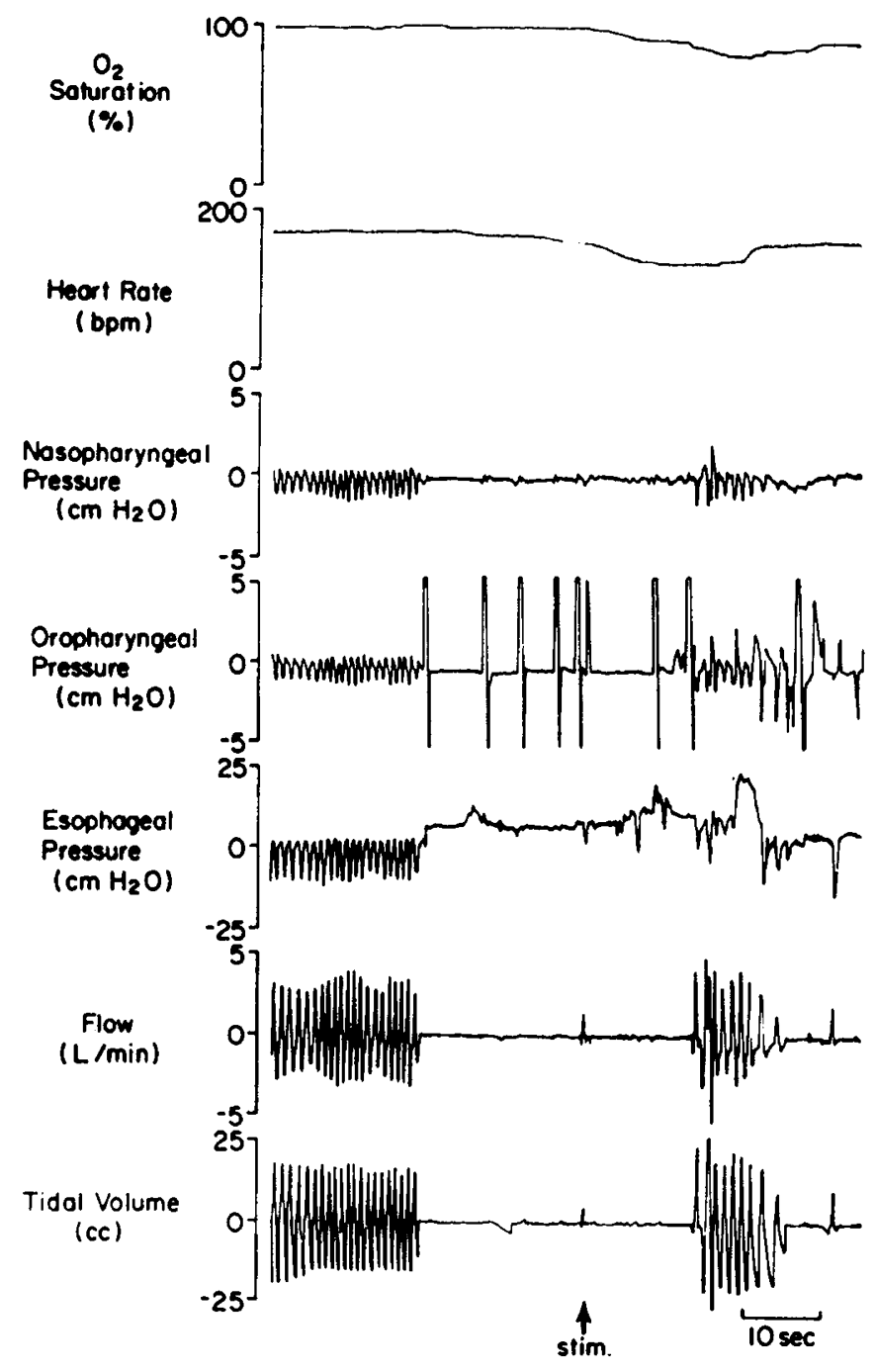

Figure 1. Characteristic pattern of spontaneous swallows during a mixed apnea. When the apnea continued beyond $15 \mathrm{~s}$, tactile stimulation of the infant ( $\uparrow$ stim) was applied in an attempt to terminate the apnea.

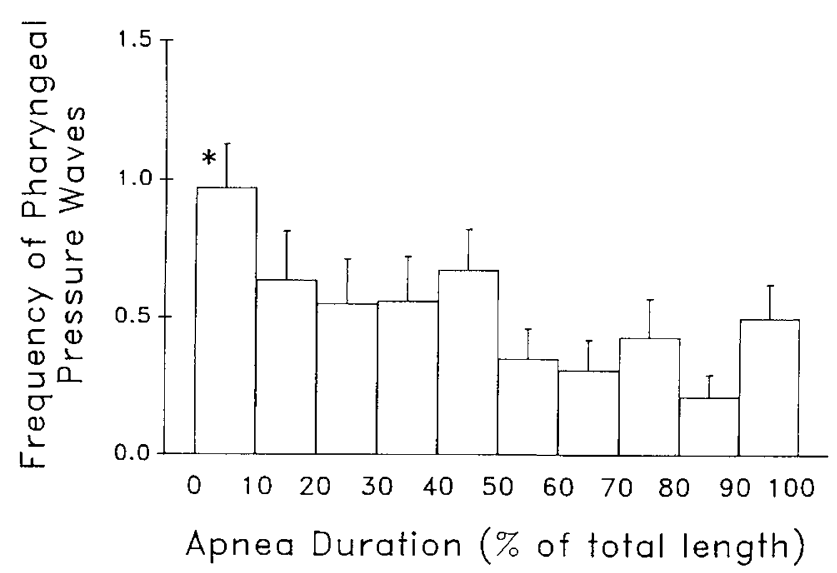

Figure 2. The frequency of pharyngeal pressure waves representing swallows was greatest at the onset of the apnea. ${ }^{*} p<0.05$, anlysis of variance. Data expressed as mean $\pm \mathrm{SD}$. Frequency $=$ number of swallows per $10 \%$ of apnea duration.

apnea, respiratory pauses of periodic breathing are not associated with an increased frequency of swallowing. Thus, this characteristic distinguishes apnea from periodic breathing. Fur-

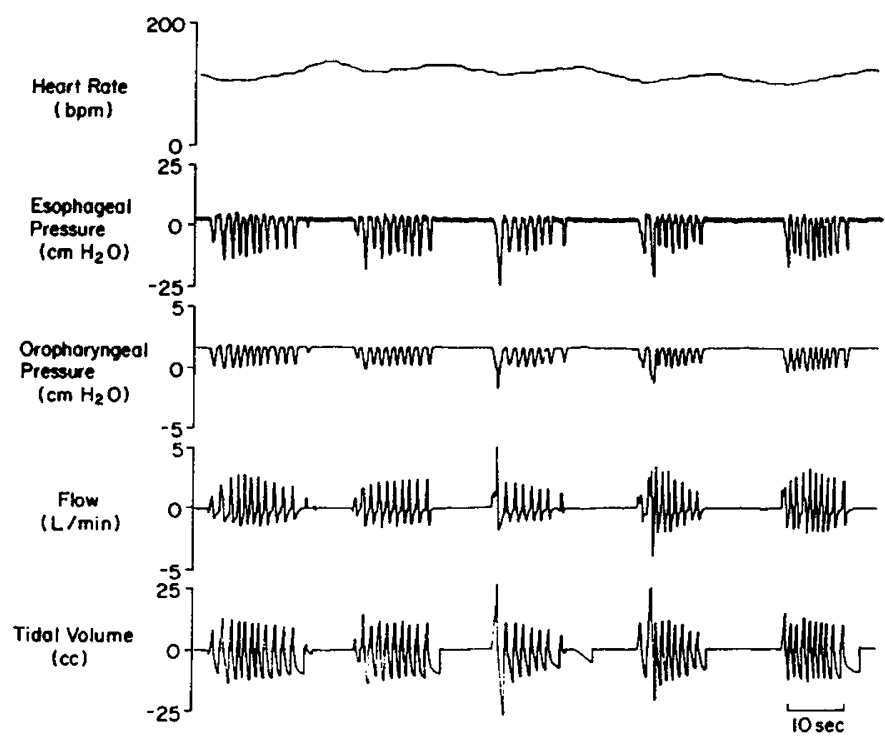

Figure 3. During the respiratory pauses of periodic breathing, swallowing, characterized by large positive pressure waves in the pharynx, did not occur.

thermore, swallowing must be initiated by a stimulus unique to the pathophysiology of apnea in infants, for an increased frequency of spontaneous swallows has not been reported during sleep apnea episodes in adults (12-15).

The origin of the swallows during apnea is not known. The coordinated muscular contractions of swallowing may be elicited by stimulation of sensory receptors in the pharynx and larynx $(16-18)$. These receptors can respond to pressure and to the chemical stimulus provided by fluids of differing composition such as water or milk. Menon et al. (9) have speculated that accumulation of pharyngeal secretions may trigger the swallows during apnea, possibly through activation of pharyngeal or laryngeal receptors. Alternatively, undetected gastroesophageal reflux may be present, before apnea, and acidic stomach contents could trigger swallows when regurgitated to the level of the larynx. In support of this theory, gastroesophageal reflux has been found to be associated with approximately $22 \%$ of apneas in premature infants (9). These postulated etiologies for swallowing infer that the swallows occur because of stimuli within the oropharynx. However, other etiologies must also be considered. Neuronal networks for swallowing and respiration exhibit reciprocal inhibition (19-21). It is possible that inhibition of respiration during apnea is associated with activation (disinhibition) of motor neurons within the swallowing center, resulting in a brief burst of swallows. These etiologies for swallowing during apnea must remain speculative, until more detailed information is available on the mechanisms by which neuronal groups which serve respiration are inhibited during apnea.

The swallows which occur during apnea could contribute to the inhibition of respiration which occurs. Wilson et al. (11) first demonstrated in infants that spontaneous swallows during sleep were associated with a $0.5-1.9-\mathrm{s}$ interruption of ventilation. Furthermore, Koenig et al. (22) have shown in infants that minute ventilation is inversely related to swallowing frequency during feeding. Inhibition of respiration during swallowing has also been elicited in animal models using direct recording of respiratory neural output from the medulla. In the anesthetized cat, Sumi (23) 
observed that swallowing elicited by water boluses in the pharynx directly inhibited firing of inspiratory neurons in the medulla. Takagi et al. (24) demonstrated in the anesthetized, adult cat that reflexes from the upper and lower pharynx interact with and modulate respiration. Thus, there is evidence from a variety of human and animal studies to support the concept of direct inhibition of respiration during swallowing. While swallows could theoretically prolong the respiratory inhibition of an apnea, they cannot be the initiating event for all apneas, because a swallow occurred within $3 \mathrm{~s}$ of cessation of airflow in only $58 \%$ of apneas.

Insertion of a catheter into the oropharynx, as used in this investigation for pressure measurement, could have triggered spontaneous swallows during sleep. This stimulus could not account for the difference in swallow frequency during apnea and period breathing, for instrumentation technique was identical in both groups of infants. Furthermore, Menon et al. (9) have previously found that insertion of a catheter into the pharynx did not alter the frequency of spontaneous swallows during apnea.

Apnea and periodic breathing share a number of characteristics: both are observed in the newborn period and exhibit a higher incidence in premature infants. Both forms of respiratory instability have been observed to decline in frequency after birth over a 5-10-wk period, depending on the degree of the baby's prematurity (25-27). The respiratory pause in both apnea and periodic breathing is preceded by a decline in tidal volume and a prolongation of respiratory time, and both may be accompanied by obstructed breaths before the onset of cycles of respiration $(6,8)$. Apnea and periodic breathing differ, however, in the following respects: the respiratory pauses of apnea are not limited in duration, and, as this study confirms, apnea in premature infants is accompanied by frequent swallows. These comparisons do not, however, allow us to deduce the nature of the neurologic events which initiate either disorder. Indeed, it is possible that different forms of inhibitory input may evoke the respiratory patterns of apnea or periodic breathing through a final common pathway to the phrenic motoneurons. Further understanding of the etiology of these disorders must await a description of their neuroanatomic substrate, and will have to take into consideration the complex interactions between respiratory drive and deglutition.

\section{REFERENCES}

1. Alden ER, Mandelkorn T, Woodrum DE, Wennberg RP, Parks CR, Hodson WA 1972 Morbidity and mortality of infants weighing less than 1000 grams in an intensive care nursery. Pediatrics 50:40 -49
2. Daily WJR, Klaus M, Meyer HBP 1969 Apnea in premature infants: Monitoring, incidence, heart rate changes, and an effect of environmental temperature. Pediatrics 43:510-518

3. Kattwinkel J, Nearman HS, Fanaroff AA, Katona PG, Klaus MH 1975 Apnea of prematurity. J Pediatr $86: 588-592$

4. Miller HC, Behrle FC, Smull NW 1959 Severe apnea and irregular respiratory rhythms among premature infants. Pediatrics 23:676-685

5. Steinschneider A 1972 Prolonged apnea and the sudden infant death syndrome: clinical and laboratory observations. Pediatrics 50:646 -654

6. Miller MJ, Carlo WA, DiFiore JM, Martin RJ 1988 Airway obstruction during periodic breathing in premature infants. J Appl Physiol 64:2496-2500

7. Kelly DH, Golub H, Carley D, Shannon DC 1986 Pneumograms in infants who subsequently died of sudden infant death syndrome. J Pediatr 109:249-254

8. Miller MJ, Petrie TG, DiFiore JM 1993 Changes in resistance and ventilatory timing that accompany apnea in premature infants. J Appl Physiol 75:720-723

9. Menon AP, Schefft GL, Thach BT 1984 Frequency and significance of swallowing during prolonged apnea in infants. Am Rev Respir Dis 130:969-973

10. Miller MJ, Carlo WA, Martin RJ 1985 Continuous positive airway pressure selectively reduces obstructive apnea in preterm infants. J Pediatr 106:91-94

11. Wilson SL, Thach BT, Brouillette RT, Abu-Osba YK 1981 Coordination of breathing and swallowing in human infants. J Appl Physiol Respir Environ Exercise Physiol 50:851-858

12. Gastaut H, Tassinari CA, Duron B 1965 Etude polygraphique des manifestations episodiques (hypniques et respiratoires) diurnes nocturnes, du syndrome de Pockwick. Rev Neurol 112:568-579

13. Walsh RE, Michaelson ED, Harkleroad LE, Zighelboim A, Sackner MA 1972 Upper airway obstruction in obese patients with sleep disturbance and somnolence. Ann Intern Med 76:185-1.92

14. Remmers JE, DeGroot WJ, Sauerland EK, Anch AM 1978 Pathogenesis of upper airway occlusion during sleep. J Appl Physiol 44:931-938

15. Cohn MA, Sackner MA 1986 Clinical spectrum of the sleep apnea syndrome. In: Edelman NH, Santiago TV (eds) Breathing Disorders of Sleep. Churchill Livingston, New York, pp 181-196

16. Storey $\mathrm{T}$, Johnson $\mathrm{P} 1975$ Laryngeal water receptors initiating apnea in the lamb. Exp Neurol 47:42-55

17. Lawson EE 1981 Prolonged central respiratory inhibition following reflex induced apnea. J Appl Physiol 50:874-879

18. Perkett EA, Vaughan RL 1982 Evidence for a laryngeal chemoreflex in some human preterm infants. Acta Paediatr Scand 71:969-972

19. Sumi T 1963 Neuronal mechanisms in swallowing. Pflugers Arch 278:647-677

20. Timms BJM, DiFiore JM, Martin RJ, Miller MJ 1993 Increased respiratory drive as an inhibitor of oral feeding of preterm infants. J Pediatr 123:127-131

21. Miller AJ 1982 Deglutition. Physiol Rev 62:129-184

22. Koenig JS, Davies AM, Thach BT 1990 Coordination of breathing, sucking and swallowing during bottle feedings in human infants. J Appl Physiol 69:1623-1629

23. Sumi $T 1963$ The activity of brain-stem respiratory neurons and spinal respiratory motoneurons during swallowing. J Neurophysiol 26:466-477

24. Takagi Y, Irwin JV, Bosma JF 1966 Effect of electrical stimulation of the pharyngeal wall on respiratory action. J Appl Physiol 21:454-462

25. Fenner A, Schalk U, Hoenicke H, Wendenburg A, Roeheing T 1973 Periodic breathing in premature and neonatal babies: incidence, breathing pattern, respiratory gas tensions, response to changes in composition of ambient air. Pediatr Res 7:174183

26. Hoppenbrouwers T, Hodgman JE, Harper RU, Hofmann E, Sterman MB, McGenty DJ 1977 Polygraphic studies of normal infants during the first six months of life. III. Incidence of apnea and periodic breathing. Pediatrics 60:418-427

27. Lee D, Caces R, Kwiatkowski K, Cates D, Rigatto H 1987 Developmental study on types and frequency distribution of short apneas ( 3 to 15 seconds) in term and preterm infants. Pediatr Res 22:344 